\title{
Cognitive Behaviour Therapy for Psychosis: Insights from Neuroimaging
}

Veena Kumari and Taylor Terca

Research and Development, Sovereign Health Group, San Clemente, CA, USA

\section{Correspondence to:}

Veena Kumari, $\mathrm{PhD}$

Research and Development

Sovereign Health Group, 1211 Puerta Del Sol,

San Clemente, CA 92673, USA

E-mail:v.kumari@sovhealth.com

Received: March 31, 2017

Accepted: June 02, 2017

Published: June 07, 2017

Citation: Kumari V, Terca T. 2017. Cognitive Behaviour Therapy for Psychosis: Insights from Neuroimaging. J Neuroimaging Psychiatry Neurol 2(1): 11-19.

Copyright: (C) 2017 Kumari and Terca. This is an Open Access article distributed under the terms of the Creative Commons Attribution 4.0 International License (CC-BY) (http:// creativecommons.org/licenses/by/4.0/) which permits commercial use, including reproduction, adaptation, and distribution of the article provided the original author and source are credited.

Published by United Scientific Group

\begin{abstract}
Up to $40 \%$ of schizophrenia patients continue to suffer from distressing symptoms despite remaining compliant with their prescribed antipsychotic medication. Additional symptom reduction following cognitive behaviour therapy for psychosis (CBTp) has been shown, but only in about $50 \%$ of such patients. A clear understanding of the neural changes following CBTp (potential mediators of improvement in target outcomes) as well as neural predictors of CBTp-led improvement (possible moderators) may help to refine or develop it further and increase its effectiveness. We provide a review of studies published to date $(9$ in total) examining the neural effects and/or predictors of CBTp. The studies analysed comprised of one spectroscopic imaging study on pre- vs post-CBTp changes, five functional magnetic resonance imaging studies [two analysing prevs post-CBTp changes, two analysing pre-therapy brain properties as predictors of symptom reduction following CBTp, and one analysing pre- vs post-CBTp changes in functional connectivity as the predictors of long term (over 7 years) outcome following $\mathrm{CBTp}$ ], and three structural magnetic resonance imaging studies [two on pre-therapy brain properties as predictors of symptom change following CBTp, and one analysing pre- vs post-CBTp changes]. The findings from pre- vs post-CBTp brain activation studies demonstrate that $\mathrm{CBTp}$ reduces fronto-limbic activation to social threat and normalises cortico-limbic functional connectivity, indicating improved affect regulation through top-down control after CBTp. Additionally, CBTp was found to reduce pituitary volume, potentially by lowering of symptom-related distress. The findings from studies analysing pre-therapy brain properties as predictors of symptom reduction following CBTp indicate that functional and structural properties of multiple brain areas that are implicated in a range of cognitive functions, particularly the dorsolateral (cognitive flexibility), medial (self-awareness) and inferior (verbal skills) frontal cortices, hippocampus (memory) and precuneus (self-awareness), predict symptom reduction following CBTp. These results suggest a role for cognitive enhancement in the context of CBTp.
\end{abstract}

\section{Keywords}

Schizophrenia, CBT, Threat, MRI, Brain activity, Functional connectivity

\section{Introduction}

Antipsychotic drugs reduce positive psychotic symptoms in the majority of acutely-ill schizophrenia patients [1, 2]. The long-term outcome, however, remains disappointing for up to $40 \%$ of patients who, despite remaining compliant with their prescribed antipsychotic medication, continue to experience one or more distressing symptoms [3-5]. A number of randomised control trials have 
Table 1: Reviewed studies of the impact of CBTp (pre- vs post-CBTp) on brain structure and function as well as brain predictors of symptom reduction following CBTp in people with psychosis.

\begin{tabular}{|c|c|c|c|c|}
\hline \multicolumn{5}{|c|}{ Neural Changes: Pre- vs Post-CBTp } \\
\hline Authors & $\begin{array}{l}\text { Imaging Modality } \\
\text { (Brain Regions } \\
\text { Examined) }\end{array}$ & Participants and Design & Task [Contrast] & Main Findings \\
\hline $\begin{array}{l}\text { Premkumar } \\
\text { et al. (2010) } \\
\text { [24] }\end{array}$ & $\begin{array}{l}\text { Spectroscopic } \\
\text { imaging (anterior } \\
\text { cingulate cortex) }\end{array}$ & $\begin{array}{l}24 \text { outpatients, } 11 \text { of whom received } \\
6-9 \text { months of CBTp in addition to } \\
\text { their usual treatment (CBTp+TAU; } \\
\text { final } n=7 \text { with usable imaging data) } \\
\text { and } 13 \text { received treatment-as- } \\
\text { usual (TAU; final } n=4) .15 \text { healthy } \\
\text { controls. } \\
\text { Patients scanned and had their } \\
\text { symptoms [33] assessed on two } \\
\text { occasions: at baseline and } 8-9 \\
\text { months later (follow-up). } \\
\text { Healthy controls examined once only. }\end{array}$ & NA & $\begin{array}{l}\text { Lower N-acetyl aspartate (NAA) } \\
\text { concentration in the anterior cingulate } \\
\text { cortex in patients at baseline relative to } \\
\text { healthy controls. } \\
\text { NAA concentration increased (trend- } \\
\text { level), in parallel to a reduction in } \\
\text { positive symptoms at follow-up relative } \\
\text { to baseline in the CBTp+TAU group. }\end{array}$ \\
\hline $\begin{array}{l}\text { Kumari et al. } \\
\text { (2011) [25] }\end{array}$ & $\begin{array}{l}\text { fMRI (whole } \\
\text { brain) }\end{array}$ & $\begin{array}{l}56 \text { outpatients, of which } 28 \text { received } \\
\text { CBTp+TAU (final } n=22 \text { ), and } 28 \\
\text { received TAU (final } n=16 \text { ). } \\
\text { All patients scanned and had } \\
\text { their symptoms assessed on two } \\
\text { occasions: at baseline and 6-8 } \\
\text { months later. }\end{array}$ & $\begin{array}{l}\text { Implicit facial affect processing } \\
\text { task. Participants presented } \\
\text { with facial expressions of } \\
\text { fear, anger, happiness as well } \\
\text { as neutral expressions (and } \\
\text { required to indicate gender), in } \\
\text { addition to a (no face) control } \\
\text { condition (happy, fearful, } \\
\text { angry and neutral expression vs } \\
\text { control condition). }\end{array}$ & $\begin{array}{l}\text { Significant reduction in PANSS } \\
\text { symptoms, particularly in delusions and } \\
\text { depression, in the CBTp+TAU group. } \\
\text { No symptom change from baseline to } \\
\text { follow-up in the TAU group. } \\
\text { Reduced activity from baseline to } \\
\text { follow-up in the threat processing } \\
\text { neural network, namely in the inferior } \\
\text { frontal, insula, thalamus, putamen and } \\
\text { occipital areas during the viewing of } \\
\text { fearful and angry facial expressions } \\
\text { found in the CBTp+TAU group, but } \\
\text { not the TAU group. } \\
\text { Significant association between the } \\
\text { degree of reduction of fMRI activity } \\
\text { during angry expressions and symptom } \\
\text { improvement. }\end{array}$ \\
\hline $\begin{array}{l}\text { Mason et al. } \\
\text { (2016) [26] }\end{array}$ & $\begin{array}{l}\text { fMRI (whole } \\
\text { brain) }\end{array}$ & $\begin{array}{l}\text { Patients: same sample and design as } \\
\text { noted above [25]. } \\
\text { In addition, } 20 \text { healthy controls } \\
\text { scanned on one occasion. }\end{array}$ & $\begin{array}{l}\text { Connectivity during the angry } \\
\text { facial expressions assessed } \\
\text { separately from left amygdala } \\
\text { and right dorsolateral } \\
\text { prefrontal cortex (DLPFC) } \\
\text { seeds. }\end{array}$ & $\begin{array}{l}\text { Symptom changes as above. } \\
\text { Concerning functional connectivity } \\
\text { patterns at baseline, greater amygdala } \\
\text { connectivity with the insula and } \\
\text { visual areas, but less connectivity with } \\
\text { somatosensory areas in in patients, } \\
\text { relative to healthy controls. } \\
\text { At follow-up, the CBTp+TAU group } \\
\text { showed normalisation of the above } \\
\text { differences (normal-like patterns). In } \\
\text { addition, CBTp+TAU showed greater } \\
\text { increases, relative to the TAU group, in } \\
\text { amygdala connectivity with DLPFC } \\
\text { and inferior parietal lobule. Latter } \\
\text { associated with reduction in positive } \\
\text { symptoms. } \\
\text { From the DLPFC seed, significantly } \\
\text { greater increase in DLPFC connectivity } \\
\text { with other prefrontal regions including } \\
\text { dorsal anterior cingulate and ventromedial } \\
\text { prefrontal cortex in the CBT+TAU group, } \\
\text { relative to the TAU group. }\end{array}$ \\
\hline $\begin{array}{l}\text { Premkumar } \\
\text { et al. (2017) } \\
{[27]}\end{array}$ & $\begin{array}{l}\text { Structural MRI } \\
\text { (pituitary volume) }\end{array}$ & $\begin{array}{l}40 \text { outpatients, of which } 24 \text { received } \\
\text { CBTp+TAU and } 16 \text { received TAU. } \\
\text { All patients scanned and had their } \\
\text { symptoms assessed on two occasions: } \\
\text { at baseline and 6-9 months later. }\end{array}$ & NA & $\begin{array}{l}\text { Symptom changes as above. } \\
\text { Pituitary volume reduced at post-CBTp } \\
\text { follow-up, relative to baseline, in the } \\
\text { CBT+TAU group. No change in the } \\
\text { TAU group. }\end{array}$ \\
\hline
\end{tabular}




\begin{tabular}{|c|c|c|c|c|}
\hline \multicolumn{5}{|c|}{ Pre-therapy Brain Properties as Predictors of Post-CBTp Symptom Reduction } \\
\hline $\begin{array}{l}\text { Kumari et al. } \\
\text { (2009) [28] }\end{array}$ & $\begin{array}{l}\text { fMRI (whole } \\
\text { brain) }\end{array}$ & $\begin{array}{l}52 \text { outpatients, } 26 \text { of whom received } \\
\text { CBTp+TAU (final } \mathrm{n}=19 \text { ) and } 26 \\
\text { continued with TAU alone (final n } \\
=17 \text { ). } 20 \text { healthy controls. } \\
\text { All patients and controls scanned } \\
\text { at baseline. Symptoms in patients } \\
\text { assessed on two occasions: at } \\
\text { baseline and } 6-8 \text { months later. }\end{array}$ & $\begin{array}{l}\text { Parametric n-back task. Block } \\
\text { design. (0-back, 1-back, 2-back } \\
\text { blocks vs rest; 1-back and 2-back } \\
\text { vs 0-back). }\end{array}$ & $\begin{array}{l}\text { No difference in working memory } \\
\text { performance or symptoms between the } \\
\text { CBT+TAU and TAU groups at baseline. } \\
\text { Baseline to follow-up change in symptoms } \\
\text { in only the CBT+TAU group. } \\
\text { Stronger DLPFC activity (within the } \\
\text { normal range) and DLPFC-cerebellum } \\
\text { connectivity during the highest memory } \\
\text { load condition (2-back > 0-back) } \\
\text { correlated with post-CBT reduction in } \\
\text { symptoms. }\end{array}$ \\
\hline $\begin{array}{l}\text { Kumari et al. } \\
\text { (2010) [29] }\end{array}$ & $\begin{array}{l}\text { fMRI (whole } \\
\text { brain) }\end{array}$ & $\begin{array}{l}52 \text { outpatients, } 26 \text { of whom received } \\
\text { CBTp+TAU (final } n=20 \text { ) and } 26 \\
\text { continued with TAU alone (final n } \\
=18 \text { ). } 20 \text { healthy controls. } \\
\text { All patients and controls scanned } \\
\text { at baseline. Symptoms in patients } \\
\text { assessed on two occasions: at } \\
\text { baseline and } 6-8 \text { months later. }\end{array}$ & $\begin{array}{l}\text { Verbal self-monitoring task } \\
\text { (event-related design) requiring } \\
\text { participants to read single words } \\
\text { presented on screen and then } \\
\text { decide based on verbal feedback } \\
\text { relayed back to them whether the } \\
\text { speech they heard was in their } \\
\text { own voice or someone else's. The } \\
\text { feedback was given in (a) their } \\
\text { own voice (self-undistorted), } \\
\text { (b) their own voice lowered } \\
\text { in pitch by } 4 \text { semitones (self- } \\
\text { distorted), (c) voice of another } \\
\text { person matched on participant's } \\
\text { sex (other-undistorted), or (d) } \\
\text { another person's voice with the } \\
\text { pitch lowered by } 4 \text { semitones } \\
\text { (other-distorted). }\end{array}$ & $\begin{array}{l}\text { No difference in performance or } \\
\text { symptoms between the CBT+TAU and } \\
\text { TAU groups at baseline. } \\
\text { Baseline to follow-up change in } \\
\text { symptoms in only the CBT+TAU group. } \\
\text { Less inferior frontal gyrus and thalamic } \\
\text { activation in patients, relative to controls. } \\
\text { Post-CBT reduction in symptoms } \\
\text { correlated with (i) greater left inferior } \\
\text { frontal gyrus activation during accurate } \\
\text { monitoring, especially of own voice, (ii) } \\
\text { less inferior parietal deactivation with } \\
\text { own, relative to other's voice, and (iii) } \\
\text { less medial prefrontal deactivation and } \\
\text { greater thalamic and precuneus activation } \\
\text { during monitoring of distorted, relative to } \\
\text { undistorted, voices. }\end{array}$ \\
\hline $\begin{array}{l}\text { Premkumar } \\
\text { et al. (2009) } \\
{[30]}\end{array}$ & $\begin{array}{l}\text { Structural MRI } \\
\text { (voxel-based- } \\
\text { morphometry, } \\
\text { whole brain) }\end{array}$ & $\begin{array}{l}60 \text { outpatients, } 30 \text { of whom } \\
\text { received CBTp+TAU (final } n=25 \text { ) } \\
\text { and } 30 \text { received TAU (final } n=19 \text { ). } \\
25 \text { healthy controls. } \\
\text { All patients and controls scanned } \\
\text { at baseline. Symptoms in patients } \\
\text { assessed on two occasions: at } \\
\text { baseline and 6-8 months later. }\end{array}$ & NA & $\begin{array}{l}\text { At baseline, no difference between } \\
\text { the CBT+TAU and TAU groups in } \\
\text { symptoms. Reduced symptoms at } \\
\text { follow-up, relative to baseline, in only } \\
\text { the CBTp+TAU group. } \\
\text { In the CBTp+TAU group, reduction } \\
\text { at follow-up in: (i) positive symptoms } \\
\text { associated with greater right cerebellum } \\
\text { grey matter volume (ii) negative symptoms } \\
\text { associated with greater left precentral } \\
\text { gyrus and right inferior parietal lobule } \\
\text { grey matter volumes, and (iii) general } \\
\text { psychopathology associated with greater } \\
\text { right superior temporal gyrus, cuneus and } \\
\text { cerebellum grey matter volumes. }\end{array}$ \\
\hline $\begin{array}{l}\text { Premkumar } \\
\text { et al. (2014) } \\
{[31]}\end{array}$ & $\begin{array}{l}\text { Structural MRI } \\
\text { (orbitofrontal } \\
\text { cortex) }\end{array}$ & $\begin{array}{l}30 \text { outpatients who received } \\
\text { CBTp+TAU (final } n=25 \text { ) for 6-9 } \\
\text { months and } 25 \text { healthy controls. } \\
\text { All patients and controls scanned } \\
\text { at baseline. Symptoms in patients } \\
\text { assessed on two occasions: at } \\
\text { baseline and 6-8 months later. }\end{array}$ & NA & $\begin{array}{l}\text { Orbitofrontal grey matter volume not } \\
\text { significantly different between the } \\
\text { patients and control groups. } \\
\text { Association between greater orbitofrontal } \\
\text { grey matter volume (at baseline) and } \\
\text { reduction in positive symptoms (at follow- } \\
\text { up) in patients. }\end{array}$ \\
\hline \multicolumn{5}{|c|}{ Neuroimaging Predictors of Long Term Outcome Following CBTp } \\
\hline $\begin{array}{l}\text { Mason et al. } \\
\text { (2017) [32] }\end{array}$ & $\begin{array}{l}\text { fMRI (whole } \\
\text { brain) }\end{array}$ & $\begin{array}{l}22 \text { CBT+TAU patients of Mason } \\
\text { et al. [26]. Monthly ratings of } \\
\text { psychotic and affective symptoms } \\
\text { obtained retrospectively across } \\
8 \text { years since receiving CBTp. } \\
\text { Additionally, self-reported recovery } \\
\text { evaluated at final follow-up. }\end{array}$ & $\begin{array}{l}\text { Task as noted above for } \\
\text { Kumari et al. [25] } \\
\text { Post-CBTp changes in } \\
\text { connectivity during the angry, } \\
\text { fearful and happy facial } \\
\text { expressions assessed separately } \\
\text { from left amygdala and right } \\
\text { DLPFC seeds [26]. Examined } \\
\text { as predictors of long term } \\
\text { recovery. }\end{array}$ & $\begin{array}{l}\text { Long-term psychotic symptoms predicted } \\
\text { by changes in prefrontal connections } \\
\text { during happy (prosocial) facial affect } \\
\text { processing. Long-termaffective symptoms } \\
\text { predicted by amygdalo-inferior parietal } \\
\text { lobule connectivity during threatening } \\
\text { facial expressions. Higher subjective } \\
\text { ratings of recovery at long-term follow- } \\
\text { up predicted by in DLPFC connectivity } \\
\text { with amygdala during threatening facial } \\
\text { expressions. }\end{array}$ \\
\hline
\end{tabular}

MRI: magnetic resonance imaging; fMRI: functional MRI; CBTp: cognitive behaviour therapy for psychosis; TAU: treatment-as-usual. DLPFC: dorsolateral prefrontal cortex 
shown that persistent symptoms, particularly delusions and depression, can be reduced by cognitive behaviour therapy for psychosis (CBTp) in such patients with medication-refractory symptoms [6-8]. More recent studies also indicate a role for CBT $\mathrm{p}$ in the prevention of psychosis $[9,10]$.

Beck's cognitive model of psychopathology [11], which provided the framework for CBT for depression about 50 years ago, stipulates that problematic behavioural and emotional responses result from an individual's biased processing of external and/or internal information. Since then, CBT has been applied [12] in varied forms, depending upon the cognitive formulation of the disorder and target outcomes, to reduce symptoms in several psychiatric disorders, including psychosis [13]. Psychological models of CBT for psychosis, commonly referred to as CBTp $[14,15]$ propose that changes in patients' appraisal of their condition and psychotic experiences help ameliorate their symptoms. Key mechanisms of this approach include modifying patients' feelings of lack of control over their symptoms, diminishing their negative overall view of themselves and the world, and altering their exaggerated negative emotionality $[14,15]$. The process of reappraising the distressing experiences of patients from their perspective seems relevant even in the context of effective antipsychotic treatment. It has been suggested [13] that antipsychotics may reduce acute psychotic symptoms (e.g. delusions) by "dampening the salience" of the abnormal experiences that caused or contributed to their formation, but they do not "erase" the symptoms. Symptom relief in the longer run may require the patients to "work through" and reappraise their experiences [16].

CBTp is recommended for the treatment of psychosis both in the UK [17] and in the US [18]. However, not all patients respond equally well to it. Symptom reduction with CBTp is seen with modest effect sizes and found to a noticeable degree in only about $50 \%$ of patients who undergo this therapy [6-8]. Furthermore, according to a recent meta-analysis, the effect size for symptom reduction following CBTp may be even smaller when sources of potential bias, such as masking of outcome assessments, are controlled for [19]. However, the effect sizes for other target outcomes, such as diminished distress or decreased preoccupation with symptoms, reduced depression and emotional difficulties, heightened social and occupational functioning, and improved overall quality of life (which have not been systematically examined or included in meta-analytic reviews) may be larger [20,21].

There is clearly a need for a better understanding of when and why CBTp works. It is reasonable to expect that neuroimaging studies identifying i) the impact of CBTp on brain structure or function, and ii) the (pre-CBTp) brain predictors of CBTp response would offer insight into possible mediators and moderators of CBTp effects. Specifically, the knowledge of which brain processes respond favourably to CBTp (possible mediators of improvement in target outcome) and which brain processes facilitate them (possible moderators of improvement) may help to develop and refine CBT $\mathrm{p}$ further to augment its efficacy.

The aim of this review is to appraise published studies that have examined the neural effects and/or predictors of effective CBTp in schizophrenia and consider the implications of their findings for future developments of CBTp. Although there have been recent reviews of brain changes following psychological therapies more generally [22, 23], none have focused specifically on the brain correlates or predictors of CBTp effectiveness.

\section{Literature Search}

We conducted a comprehensive literature search of electronic databases (PubMed and Web of Science) using the search term ("psychosis" OR "psychotic" OR "schizophrenia" OR "schizophrenic") AND ("cognitive behav* therapy" OR "CBT") AND ("neuroimaging” OR "MRI" OR "Magnetic Resonance" OR "fMRI" OR "MRI"). The search was run on 12th May 2017 with no time range specified for the date of publication. Our search revealed 9 papers in total [24-32], all published within the last 10 years (see Table 1 for greater details).

\section{Results}

The main findings of the reviewed studies are summarised in Table 1.

\section{Pre- vs post-CBT $p$ changes}

So far four reports [24-28], all published within the last 7 years and with overlapping samples from the same research group, have focused on pre- vs post-CBTp brain changes in psychosis. Of these, one study [24] used spectroscopic imaging, two studies used functional magnetic resonance imaging (fMRI) [25-26], and one study used structural magnetic resonance imaging (MRI) [27]. The findings of each of these are described and discussed below.

\section{Spectroscopic imaging}

Premkumar and colleagues [24] used spectroscopic imaging to investigate the changes following CBTp. Their study provided preliminary evidence for $\mathrm{N}$-acetyl aspartate (NAA) concentration in the anterior cingulate cortex (ACC) to increase following 6-8 months of NICE (National Institute for Clinical Excellence, UK)-compliant CBTp [17], adjunct to treatmentas-usual, in a small group of medication-resistant schizophrenia patients. The increase in ACC NAA was concomitant with improvement in positive symptoms, as assessed by the positive and negative syndrome scale (PANSS) [33]. No change in ACC NAA was found in a matched group of patients who were also studied over the same time scale but did not receive CBTp. Furthermore, at baseline, ACC NAA concentration was lower in patients than matched healthy controls and correlated negatively with positive and general psychopathology symptoms scores. Although a neural change was observed in this study following CBTp, it may not tell us much about the specific mechanisms of CBTp action since the use of atypical (but not typical) antipsychotic drugs is also known to be accompanied with increased ACC NAA levels in both recent-onset cases and patients with chronic illness [34, 35]. 


\section{fMRI}

In the first study using fMRI, Kumari and colleagues [25] examined 56 outpatients with one or more persistent distressing positive symptoms of schizophrenia, 28 of whom received CBTp for 6-8 months in addition to their usual treatment (CBTp+TAU), and 28 received treatment-as-usual (TAU). All patients underwent fMRI during an implicit affect processing task (gender discrimination) at baseline and the end-of-treatment follow-up. They had their symptoms assessed by a clinician blind to treatment group on both occasions (baseline and follow-up). The CBTp+TAU and TAU groups were comparable at baseline in terms of clinical and demographic characteristics and neural and behavioural responses to affective and neutral facial expressions. There was significant reduction in PANSS symptoms, particularly in delusions and depression, in the CBTp+TAU group, relative to the TAU group, which did not show significant symptom change from baseline to follow-up. The CBTp+TAU group, but not the TAU group, showed reduced activity from baseline to follow up in the threat processing neural network, namely in the inferior frontal, insula, thalamus, putamen and occipital areas during the viewing of fearful and angry facial expressions. The degree of reduction of fMRI activity during angry expressions correlated directly with symptom improvement. This study provided the first empirical evidence that effective CBTp reduces brain responses to social threat and most likely mediates symptom reduction by promoting processing of threats in a less distressing way. The areas showing reduced activation after CBT $\mathrm{p}$ are known to be involved in the detection and processing of threat [36] and can be expected to change following CBTp, possibly in association with a reduction in subjective experience of threat and distress following CBTp. Interestingly, post-CBT changes in many of the areas involved in threat processing have also been seen in depression and anxiety disorders [22]. This is perhaps not surprising given that CBT across disorders [12] aims to modify appraisals of physiological, cognitive and affective states and normalise (otherwise distorted) construction of experiences.

A later study [26] examined functional connectivity during social threat (angry expressions) separately from left amygdala and right dorsolateral prefrontal cortex (DLPFC) seeds in the sample reported earlier by Kumari et al. [25] to further examine the mechanisms underlying CBTp-led changes in threat processing and appraisal. The findings revealed that patients who received CBTp+TAU, but not those who received TAU, displayed normalised amygdala connectivity with the insula and visual areas (i.e. functional connectivity patterns showing amygdala connectivity with the insula and visual areas after, but not before, CBTp). They also showed greater increases in amygdala connectivity with DLPFC and inferior parietal lobule, with the latter associating with positive symptom improvements. From the DLPFC seed, the group which received $\mathrm{CBT}+\mathrm{TAU}$ showed a significantly greater increase in DLPFC connectivity with other prefrontal regions, including the dorsal anterior cingulate and ventromedial $\mathrm{PFC}$, relative to the TAU group. These findings suggest that CBTp boosts connectivity between higher-order cognitive systems and those involved in threat and salience processing.
Furthermore, these results are in line with the suggestion that appropriate affect modulation requires the modulation of ventral and limbic regions by DLPFC through top-down connectivity [37].

\section{Structural MRI}

Very recently, Premkumar and colleagues [27] examined possible changes in pituitary volume in a subsample of patients who took part in the earlier study by Kumari and colleagues [25]. Pituitary volume was found to be reduced at post-CBTp follow-up, relative to baseline, in those who received CBT $\mathrm{p}$ in addition to their usual treatment but not in those who remained in treatment-as-usual. Since the pituitary is involved in stress regulation [38], this finding most likely reflects enhanced stress regulation and lowering of symptomrelated distress.

\section{Neuroimaging predictors: pre-therapy brain properties as predictors of symptom reduction following CBT $\mathbf{p}$}

The integrity of brain areas involved in the top-down processing of information is postulated to be associated with CBT responsiveness across disorders [39-41]. Most psychiatric disorders are associated with neurocognitive deficits to some degree. These deficits, despite skilled therapy adaptations to compensate for them, may hamper effective CBT by impeding patients' ability to remember information discussed during therapy sessions, to acquire new, more flexible thinking styles or coping strategies, or to generalise specific issues discussed during therapy session to other situations. Consistent with this notion, there is empirical evidence to suggest that pretherapy level of cognitive function, in particular executive function [42-45] and the integrity of associated neural structures $[46,47]$, influence the response to CBT for anxiety and depression, particularly in older adults who are likely to be cognitively compromised at least to some degree. Pretherapy level of neurocognitive function is likely to be an even stronger predictor of CBTp response in schizophrenia than the association seen in anxious, depressed or aged population, since this clinical population, on average, is known to be characterized by a range of neurocognitive deficits $[48,49]$.

\section{Functional MRI}

Of the two studies that used fMRI to examine neural predictors of CBTp responsiveness, the first study [28] examined the association between pre-therapy brain activity within the working memory neural network and clinical response to CBTp. Stronger bilateral DLPFC activation (but within the normal range) during the memory load condition was found to be positively associated with post-CBTp clinical improvement. In addition, positive connectivity between the left DLPFC and cerebellum and reduced deactivation of the default network regions were strongly associated with a favourable response to CBTp. Of various fronto-parietal regions normally activated by the n-back task (see Table 1 for task details), the DLPFC contributes primarily to executive processes such as noting the contents of working memory [50, 51] and executive control of maintenance and manipulation [52]. The DLPFC is also critical for relational processing in 
decision-making [53] and top-down control [54]. It can be inferred from these results that patients with relatively intact DLPFC function were more capable of schema induction (facilitating transfer of learning from one situation to other, similar, situations), reasoning, and relational processing (pooling together and comparing decision-relevant information), and thus they benefited the most from CBTp. An interesting observation of this study was, although DLPFC activity of both hemispheres was associated with a favourable response to CBTp, the left DLPFC showed a more robust pattern of activity and connectivity with the cerebellum in association with $\mathrm{CBTp}$ responsiveness. This finding suggests that left hemisphere resources (verbal processing) may be crucial for a beneficial outcome of CBTp, as reported previously for CBT for depression [55]. This potential association between the left DLPFC-cerebellum connectivity and a favourable CBTp response may reflect cerebellar contributions to executive control [56-58]. Furthermore, the relationship between reduced deactivation of the default network regions (which are normally engaged in 'default mind-wandering states') and poor response to CBTp possibly indicates a reduced ability to focus on and/or switch to the task-at-hand in poor CBTp responders.

The second fMRI study [29] investigated whether pre-therapy brain activity during a verbal self-monitoring task [59] predicts a favourable response to CBTp. The task involved monitoring self- and externally-generated speech, which were either normal or distorted (see Table 1 for further task details). The use of various forms of speech for this investigation was motivated by the role of left hemispherebased language processes in responsiveness to $\mathrm{CBT}$ for depression [55], language pathway abnormalities in psychosis $[60,61]$, and the earlier finding concerning the left DLPFC response associating somewhat more strongly than the right DLPFC response with CBTp effectiveness [28]. The findings revealed positive associations between a favourable response to CBTp and greater left inferior frontal gyrus activity during accurate monitoring, especially of own voice. The results also showed less inferior parietal deactivation/slight activation with monitoring own voice relative to someone else's and less medial prefrontal deactivation and greater thalamic and precuneus activation with monitoring of distorted voices relative to undistorted voices. All greater activations were within the normal range (i.e. not hyper-activated in patients relative to healthy participants). The left inferior frontal gyrusCBTp response association observed in this study was in line with earlier findings in the context of CBT for depression [55] and well explained by known involvement of the left inferior frontal gyrus (Broca's area) in speech and language processing [62] and verbal working memory [50]. The thalamus is involved in attention [63] while the medial prefrontal, inferior parietal and precuneus regions are implicated in self-awareness, selfrepresentation and reflection of own experiences [64-66]. Given these functions, the findings can be taken to suggest that patients with relatively preserved language processing (left inferior frontal gyrus), attention (thalamus), and insight and self-awareness (medial prefrontal, inferior parietal, precuneus) benefitted most from CBT $\mathrm{p}$.

\section{Structural MRI}

Of the two structural MRI studies, the first study [30] used voxel-based morphometry to examine the association between pre-therapy grey matter volume across the whole brain and reduction in symptoms following CBTp. The findings showed positive associations between CBTp-led improvement in symptoms and grey matter volume in a number of localised regions, particularly in the cerebellum, superior temporal gyrus and the parietal lobe. Although this study was exploratory in that it examined CBTp associations with voxels across the whole brain, the observed grey matter volume-CBTp response associations appear meaningful. Disruption in the cortico-cerebellar-thalamo-cortical circuitry has been theorised to result in deficient processing, prioritising, retrieval, coordination, and responding to information in schizophrenia [67]. Several studies have confirmed cerebellar contributions to higher order cognitive functions, such as task management and multi-tasking components of executive processing $[56,57]$. There is evidence for the involvement of the parietal lobe in both working and episodic memory [68]. GMV of the superior temporal gyrus is positively associated with abstraction ability [69] and awareness of symptoms and attributing them to illness in patients with schizophrenia [70]. Perhaps the most interesting finding of this study was that CBTp+TAU responders (11/25 showing >20\% improvement from baseline on total PANSS scores) had greater hippocampal volume relative to $\mathrm{CBT}$ + $\mathrm{TAU}$ non-responders. Hippocampal volume is known to correlate positively with verbal learning and memory in schizophrenia [71] and there is evidence from another research group for impaired verbal memory to be a limiting factor in the context of CBTp [72]. Patients with greater grey matter volume in the areas associated with a good CBTp response were perhaps relatively better at coordination of mental activity, cognitive flexibility, verbal learning, and memory, all of which can be expected to facilitate CBTp. A more recent study [31], using a region-of-interest approach and the same sample reported previously by Premkumar and colleagues [30], demonstrated an association between larger grey matter volume of the orbitofrontal cortex and symptom reduction following CBTp. This association is most likely explained by the role of orbitofrontal cortex in emotional decision-making and cognitive flexibility [73].

\section{Neuroimaging predictors of long term outcome following CBTp}

CBTp has been reported to produce continued improvements at a longer follow-up (e.g. 9 months after the end of CBTp) [74] and reported to be associated with better longer term outcomes (e.g. lower symptom levels 5 years after the end of CBTp) [75]. Very recently, Mason and colleagues [32] examined and detected a positive association between some of the cortico-limbic connectivity changes observed immediately following CBTp [27] and clinical outcomes over a 7 year period. These findings highlighted the importance of neuroimaging in the context of improved longer term outcome in schizophrenia and perhaps other psychiatric disorders.

\section{Implications: future research and therapeutic avenues}

All published studies examining the neural effects and 
predictors of CBTp so far arise from an overlapping sample of outpatients with fully or partially medication resistant symptoms. Nonetheless, their findings have important implications both at the theory level and clinical practice level. At the theory level, the findings concerning the effects of CBTp on brain functions [25-27] agree with current psychological models of CBTp $[14,15]$, which state CBTp aims for a reappraisal of, and a reduction in distress in response to, signals of potential direct threat (e.g. distressing voices or eye contact from strangers). To further elucidate the mechanisms of CBTp, future studies should aim to clarify whether CBTp normalises fronto-limbic activations to threatening stimuli via its effect on conscious processing of emotional information (help patients re-interpret and disengage from threat-related information), early unconscious emotion processing (addressing hypervigilance, pre-attentive bias to threat), or both. Such a distinction is important because both a pre-attentive bias for detection of threat-related information as well as difficulty disengaging threat-related emotional material from conscious awareness have been implicated in delusional beliefs [76]. It would also be valuable to examine emotion regulation and worry management as possible mechanisms of CBTp $[77,78]$. Finally, future studies need to examine the neural mechanisms, especially the involvement of brain systems implicated in cognitive reappraisal of emotions [37] and recently found to predict longer term outcome [32], underlying CBTp effects on specific symptoms, such as depression and delusions [79, 80], and those that might explain improvements in other target outcomes such as reduced symptom-related distress, increased social and occupational functioning and higher wellbeing $[20,21]$.

The findings concerning the neural predictors of CBTp suggest novel avenues for future development and modification of CBTp at the clinical practice level for schizophrenia patients who appear relatively less responsive to current versions of the routine CBTp. For example, targeting insight and self-monitoring skills very early during the course of CBTp may improve the clinical benefits of CBTp. CBTp may need to be further modulated for patients with impaired executive function, memory and language processing skills. A formal pre-therapy assessment of relevant cognitive functions followed by targeted cognitive remediation therapies [81] may be helpful. There are promising data showing that cognitive remediation therapies can normalise activity in many brain areas, including the prefrontal and cingulate regions that commonly show activation deficits during working memory and affect processing paradigms in schizophrenia [82] and also found predict CBTp response [24-32].

\section{Conclusion}

Neuroimaging studies have helped to elucidate the mechanisms of effective CBTp by showing that it reduces or normalises brain response to social threat. They also highlight the importance of pre-therapy level of brain function in the context of effective CBTp. Addressing relevant brain and cognitive deficits prior to or during CBTp with cognitive enhancement therapies may improve the efficacy of CBTp.

\section{Acknowledgements}

This work received no specific grant from any funding agency in the public, commercial, or not-for-profit sectors.

\section{Conflict of Interest}

The author reports no conflict of interest.

\section{References}

1. Kasper S. 2006. Optimisation of long-term treatment in schizophrenia: treating the true spectrum of symptoms. Eur Neuropsychopharmacol 16(Suppl 3): S135-S141. https://doi.org/10.1016/j.euroneuro.2006.06.004

2. Sommer IE, Slotema CW, Daskalakis ZJ, Derks EM, Blom JD, et al. 2012. The treatment of hallucinations in schizophrenia spectrum disorders. Schizophr Bull 38(4): 704-714. https://doi.org/10.1093/ schbul/sbs034

3. Conley RR, Kelly DL. 2001. Management of treatment resistance in schizophrenia. Biol Psychiatry 50(11): 898-911.https://doi.org/10.1016/ S0006-3223(01)01271-9

4. McEvoy JP, Lieberman JA, Perkins DO, Hamer RM, Gu H, et al. 2007. Efficacy and tolerability of olanzapine, quetiapine, and risperidone in the treatment of early psychosis: a randomized, double-blind 52week comparison. Am J Psychiatry 164(7): 1050-1060. https://doi. org/10.1176/ajp.2007.164.7.1050

5. Potkin SG, Weiden PJ, Loebel AD, Warrington LE, Watsky EJ, et al. 2009. Remission in schizophrenia: 196-week, dou ble-blind treatment with ziprasidone vs. haloperidol. Int J Neuropsychopharmacol 12(9): 1233-1248. https://doi.org/10.1017/S1461145709000352

6. Burns AM, Erickson DH, Brenner CA. 2014. Cognitive-behavioral therapy for medication-resistant psychosis: a meta-analytic review. Psychiatr Serv 65(7): 874-880. https://doi.org/10.1176/appi. ps.201300213

7. Wykes T, Steel C, Everitt B, Tarrier N. 2008. Cognitive behavior therapy for schizophrenia: effect sizes, clinical models, and methodological rigor. Schizophr Bull 34(3): 523-537. https://doi.org/10.1093/schbul/sbm114

8. Zimmermann G, Favrod J, Trieu VH, Pomini V. 2005. The effect of cognitive behavioral treatment on the positive symptoms of schizophrenia spectrum disorders: a meta-analysis. Schizophr Res 77(1): 1-9. https://doi.org/10.1016/j.schres.2005.02.018

9. Addington J, Marshall C, French P. 2012. Cognitive behavioral therapy in prodromal psychosis. Curr Pharm Des 18(4): 558-565.

10. Hutton P, Taylor PJ. 2014. Cognitive behavioural therapy for psychosis prevention: a systematic review and meta-analysis. Psychol Med 44(3): 449-468. https://doi.org/10.1017/S0033291713000354

11. Beck AT. 1963. Thinking and depression. I. idiosyncratic content and cognitive distortions. Arch Gen Psychiatry 9(4): 324-333. https://doi. org/10.1001/archpsyc.1963.01720160014002

12. Beck AT. 2005. The current state of cognitive therapy: a 40-year retrospective. Arch Gen Psychiatry 62(9): 953-599. https://doi. org/10.1001/archpsyc.62.9.953

13. Butler AC, Chapman JE, Forman EM, Beck AT. 2006. The empirical status of cognitive-behavioral therapy: a review of meta-analyses. Clin Psychol Rev 26(1): 17-31. https://doi.org/10.1016/j.cpr.2005.07.003

14. Garety PA, Bebbington P, Fowler D, Freeman D, Kuipers E. 2007. Implications for neurobiological research of cognitive models of psychosis: a theoretical paper. Psychol Med 37(10): 1377-1391. https:// doi.org/10.1017/S003329170700013X

15. Kuipers E, Garety P, Fowler D, Freeman D, Dunn G, et al. 2006. Cognitive, emotional, and social processes in psychosis: refining cognitive behavioral therapy for persistent positive symptoms. Schizophr Bull 32(Suppl 1): S24-S31. https://doi.org/10.1093/schbul/sb1014 
16. Kapur S. 2003. Psychosis as a state of aberrant salience: a framework linking biology, phenomenology, and pharmacology in schizophrenia. Am J Psychiatry 160(1): 13-23. https://doi.org/10.1176/appi. ajp.160.1.13

17. NICE. 2009. National Institute for Clinical Excellence in the United Kingdom: Guidelines for Schizophrenia. Gaskell Press, London, UK.

18. Dixon LB, Dickerson F, Bellack AS, Bennett M, Dickinson D, et al. 2010 The 2009 schizophrenia PORT psychosocial treatment recommendations and summary statements. Schizophr Bull 36(1): 48-70. https://doi. org/10.1093/schbul/sbp115

19. Jauhar S, McKenna PJ, Radua J, Fung E, Salvador R, et al. 2014. Cognitive-behavioural therapy for the symptoms of schizophrenia: systematic review and meta-analysis with examination of potential bias. Br J Psychiatry 204(1): 20-29. https://doi.org/10.1192/bjp. bp.112.116285

20. Birchwood M, Trower P. 2006. The future of cognitive-behavioural therapy for psychosis: not a quasi-neuroleptic. Br J Psychiatry 188: 107108. https://doi.org/10.1192/bjp.bp.105.014985

21. Peters E. 2014. An oversimplification of psychosis, its treatment, and its outcomes? BrJ Psychiatry 205(2): 159-160. https://doi.org/10.1192/ bjp.205.2.159a

22. Barsaglini A, Sartori G, Benetti S, Pettersson-Yeo W, Mechelli A. 2014. The effects of psychotherapy on brain function: a systematic and critical review. Prog Neurobiol 114:1-14. https://doi.org/10.1016/j. pneurobio.2013.10.006

23. Mason L, Peters E, Kumari V. 2016. Functional connectivity predictors and mechanisms of cognitive behavioural therapies: a systematic review with recommendations. Aust N Z J Psychiatry 50(4): 311-321. https:// doi.org/10.1177/0004867415624970

24. Premkumar P, Parbhakar VA, Fannon D, Lythgoe D, Williams SC, et al. 2010. N-acetyl aspartate concentration in the anterior cingulate cortex in patients with schizophrenia: a study of clinical and neuropsychological correlates and preliminary exploration of cognitive behaviour therapy effects. Psychiatry Res 182(3): 251-260. https://doi. org/10.1016/j.pscychresns.2010.02.008

25. Kumari V, Fannon D, Peters ER, Ffytche DH, Sumich AL, et al. 2011 Neural changes following cognitive behaviour therapy for psychosis: a longitudinal study. Brain 134(Pt 8): 2396-2407. https://doi. org/10.1093/brain/awr154

26. Mason L, Peters ER, Dima D, Williams SC, Kumari V. 2016. Cognitive behavioral therapy normalizes functional connectivity for social threat in psychosis. Schizophr Bull 42(3): 684-692. https://doi.org/10.1093/ schbul/sbv153

27. Premkumar P, Bream D, Sapara A, Fannon D, Anilkumar AP, et al. 2017. Pituitary volume reduction in schizophrenia following cognitive behavioural therapy. Schizophr Res . https://doi.org/10.1016/j. schres.2017.04.035

28. Kumari V, Peters ER, Fannon D, Antonova E, Premkumar P, et al. 2009. Dorsolateral prefrontal cortex activity predicts responsiveness to cognitive-behavioral therapy in schizophrenia. Biol Psychiatry 66(6): 594-602. https://doi.org/10.1016/j.biopsych.2009.04.036

29. Kumari V, Antonova E, Fannon D, Peters ER, Ffytche DH, et al. 2010. Beyond dopamine: functional MRI predictors of responsiveness to cognitive behaviour therapy for psychosis. Front Behav Neurosci 4: 4. https://doi.org/10.3389/neuro.08.004.2010

30. Premkumar P, Fannon D, Kuipers E, Peters ER, Anilkumar AP, et al. 2009. Structural magnetic resonance imaging predictors of responsiveness to cognitive behaviour therapy in psychosis. Schizophr Res 115(2-3): 146-155. https://doi.org/10.1016/j.schres.2009.08.007

31. Premkumar P, Fannon D, Sapara A, Peters E, Anilkumar AP, et al. 2015. Orbitofrontal cortex, emotional decision-making and response to cognitive behavioural therapy for psychosis. Psychiatry Res 231(3): 298307. https://doi.org/10.1016/j.pscychresns.2015.01.013

32. Mason L, Peters E, Williams SC, Kumari V. 2017. Brain connectivity changes occurring following cognitive behavioural therapy for psychosis predict long-term recovery. Transl Psychiatry 7(1): e1001. https://doi. org/10.1038/tp.2016.263

33. Kay SR, Fiszbein A, Opier LA. 1987. The positive and negative syndrome scale (PANSS) for schizophrenia. Schizophr Bull 13(2): 261-276.

34. Braus DF, Ende G, Weber-Fahr W, Demirakca T, Henn FA. 2001. Favorable effect on neuronal viability in the anterior cingulate gyrus due to long-term treatment with atypical antipsychotics: an MRSI study. Pharmacopsychiatry 34(6): 251-253. https://doi. org/10.1055/s-2001-18037

35. Braus DF, Ende G, Weber-Fahr W, Demirakca T, Tost H, et al. 2002. Functioning and neuronal viability of the anterior cingulate neurons following antipsychotic treatment: MR-spectroscopic imaging in chronic schizophrenia. Eur Neuropsychopharmacol 12(2): 145-152. https://doi.org/10.1016/S0924-977X(02)00003-2

36. Underwood R, Peters E, Kumari V. 2015. Psychobiology of threat appraisal in the context of psychotic experiences: a selective review. Eur Psychiatry 30(7): 817-829. https://doi.org/10.1016/j. eurpsy.2015.07.001

37. Buhle JT, Silvers JA, Wager TD, Lopez R, Onyemekwu C, et al. 2014. Cognitive reappraisal of emotion: a meta-analysis of human neuroimaging studies. Cereb Cortex 24(11): 2981-2990. https://doi. org/10.1093/cercor/bht154

38. Walker E, Mittal V, Tessner K. 2008. Stress and the hypothalamic pituitary adrenal axis in the developmental course of schizophrenia. Annu Rev Clin Psychol 4: 189-216. https://doi.org/10.1146/annurev. clinpsy.4.022007.141248

39. Kumari V. 2006. Do psychotherapies produce neurobiological effects? Acta Neuropsychiatr 18(2): 61-70. https://doi.org/10.1111/j.16015215.2006.00127.x

40. Linden DE. 2006. How psychotherapy changes the brain--the contribution of functional neuroimaging. Mol Psychiatry 11(6): 528538. https://doi.org/10.1038/sj.mp.4001816

41. Brooks SJ, Stein DJ. 2015. A systematic review of the neural bases of psychotherapy for anxiety and related disorders. Dialogues Clin Neurosci 17(3): 261-279.

42. Johnco C, Wuthrich VM, Rapee RM. 2014. The influence of cognitive flexibility on treatment outcome and cognitive restructuring skill acquisition during cognitive behavioural treatment for anxiety and depression in older adults: results of a pilot study. Behav Res Ther 57: 55-64. https://doi.org/10.1016/j.brat.2014.04.005

43. Julian LJ, Mohr DC. 2006. Cognitive predictors of response to treatment for depression in multiple sclerosis. J Neuropsychiatry Clin Neurosci 18(3): 356-363. https://doi.org/10.1176/jnp.2006.18.3.356

44. Mohlman J, Gorman JM. 2005. The role of executive functioning in CBT: a pilot study with anxious older adults. Behav Res Ther 43(4): 447465. https://doi.org/10.1016/j.brat.2004.03.007

45. Moorey S, Holting C, Hughes P, Knynenberg P, Michael A. 2001. Does problem solving ability predict therapy outcome in a clinical setting? Behav Cogn Psychother 29(4): 485-495. https://doi.org/10.1017/ S1352465801004088

46. Falconer E, Allen A, Felmingham KL, Williams LM, Bryant RA. 2013. Inhibitory neural activity predicts response to cognitive-behavioral therapy for posttraumatic stress disorder. J Clin Psychiatry 74(9): 895901. https://doi.org/10.4088/JCP.12m08020

47. Thompson DG, Kesler SR, Sudheimer K, Mehta KM, Thompson LW, et al. 2015. fMRI activation during executive function predicts response to cognitive behavioral therapy in older, depressed adults. Am J Geriatr Psychiatry 23(1): 13-22. https://doi.org/10.1016/j.jagp.2014.02.001

48. Kumari V, Cooke M. 2006. Use of magnetic resonance imaging in tracking the course and treatment of schizophrenia. Expert Rev Neurother 6(7): 1005-1016. https://doi.org/10.1586/14737175.6.7.1005

49. Reichenberg A, Harvey PD. 2007. Neuropsychological impairments in schizophrenia: integration of performance-based and brain imaging 
findings. Psychol Bull 133(5): 833-858. https://doi.org/10.1037/00332909.133.5.833

50. Wager TD, Smith EE. 2003. Neuroimaging studies of working memory: a meta-analysis. Cogn Affect Behav Neurosci 3(4): 255-274. https://doi.org/10.3758/CABN.3.4.255

51. Chase HW, Clark L, Sahakian BJ, Bullmore ET, Robbins TW. 2008. Dissociable roles of prefrontal subregions in self-ordered working memory performance. Neuropsychologia 46(11): 2650-2661. https://doi. org/10.1016/j.neuropsychologia.2008.04.021

52. Maestu F, Campo P, Capilla A, Simos PG, Paul N, et al. 2005. Prefrontal brain magnetic activity: effects of memory task demands. Neuropsychology 19(3): 301-308. https://doi.org/10.1037/0894-4105.19.3.301

53. Krawczyk DC. 2002. Contributions of the prefrontal cortex to the neural basis of human decision making. Neurosci Biobehav Rev 26(6): 631-664. https://doi.org/10.1016/S0149-7634(02)00021-0

54. Garavan H, Ross TJ, Murphy K, Roche RA, Stein EA. 2002. Dissociable executive functions in the dynamic control of behavior: inhibition, error detection, and correction. Neuroimage 17(4): 1820-1829. https://doi. org/10.1006/nimg.2002.1326

55. Bruder GE, Stewart JW, Mercier MA, Agosti V, Leite P, et al. 1997. Outcome of cognitive-behavioral therapy for depression: relation to hemispheric dominance for verbal processing. J Abnorm Psychol 106(1): 138-144. https://doi.org/10.1037/0021-843X.106.1.138

56. Bellebaum C,Daum I.2007. Cerebellar involvement in executive control. Cerebellum 6(3):184-192.https://doi.org/10.1080/14734220601169707

57. Hayter AL, Langdon DW, Ramnani N. 2007. Cerebellar contributions to working memory. Neuroimage 36(3): 943-954. https://doi. org/10.1016/j.neuroimage.2007.03.011

58. Thach WT. 2007. On the mechanism of cerebellar contributions to cognition. Cerebellum 6(3): 163-167. https://doi. org/10.1080/14734220701373530

59. Kumari V, Fannon D, Ffytche DH, Raveendran V, Antonova E, et al. 2008. Functional MRI of verbal self-monitoring in schizophrenia: performance and illness-specific effects. Schizophr Bull 36(4): 740-755. https://doi.org/10.1093/schbul/sbn148

60. Crow TJ. 2000. Schizophrenia as the price that homosapiens pays for language: a resolution of the central paradox in the origin of the species. Brain Res Brain Res Rev 31(2-3): 118-129. https://doi.org/10.1016/ S0165-0173(99)00029-6

61. Li X, Branch CA, DeLisi LE. 2009. Language pathway abnormalities in schizophrenia: a review of fMRI and other imaging studies. Curr Opin Psychiatry 22(2): 131-139. https://doi.org/10.1097/ YCO.0b013e328324bc43

62. Demonet JF, Thierry G, Cardebat D. 2005. Renewal of the neurophysiology of language: functional neuroimaging. Physiol Rev 85(1): 49-95. https://doi.org/10.1152/physrev.00049.2003

63. Adler CM, Sax KW, Holland SK, Schmithorst V, Rosenberg L, et al. 2001. Changes in neuronal activation with increasing attention demand in healthy volunteers: an fMRI study. Synapse 42(4): 266-272. https:// doi.org/10.1002/syn.1112

64. Gusnard DA, Akbudak E, Shulman GL, Raichle ME. 2001. Medial prefrontal cortex and self-referential mental activity: relation to a default mode of brain function. Proc Natl Acad Sci U S A 98(7): 42594264. https://doi.org/10.1073/pnas.071043098

65. Kircher TT, Brammer M, Bullmore E, Simmons A, Bartels M, et al. 2002. The neural correlates of intentional and incidental self-processing. Neuropsychologia 40(6): 683-692. https://doi.org/10.1016/S00283932(01)00138-5

66. Uddin LQ, Kaplan JT, Molnar-Szakacs I, Zaidel E, Iacoboni M. 2005. Self-face recognition activates a frontoparietal "mirror" network in the right hemisphere: an event-related fMRI study. Neuroimage 25(3): 926935. https://doi.org/10.1016/j.neuroimage.2004.12.018

67. Andreasen NC, Nopoulos P, O'Leary DS, Miller DD, Wassink T, et al.
1999. Defining the phenotype of schizophrenia: cognitive dysmetria and its neural mechanisms. Biol Psychiatry 46(7): 908-920. https://doi. org/10.1016/S0006-3223(99)00152-3

68. Olson IR, Berryhill M. 2009. Some surprising findings on the involvement of the parietal lobe in human memory. Neurobiol Learn Memory 91(2): 155-165. https://doi.org/10.1016/j.nlm.2008.09.006

69. Nestor PG, Shenton ME, McCarley RW, Haimson J, Smith RS, et al. 1993. Neuropsychological correlates of MRI temporal lobe abnormalities in schizophrenia. Am J Psychiatry 150(12): 1849-1855. https://doi.org/10.1176/ajp.150.12.1849

70. Cooke MA, Fannon D, Kuipers E, Peters E, Williams SC, et al. 2008. Neurological basis of poor insight in psychosis: a voxel-based MRI study. Schizophr Res 103(1-3): 40-51. https://doi.org/10.1016/j. schres.2008.04.022

71. Antonova E, Sharma T, Morris R, Kumari V. 2004. The relationship between brain structure and neurocognition in schizophrenia: a selective review. Schizophr Res 70(2-3): 117-145. https://doi.org/10.1016/j. schres.2003.12.002

72. Penadés R, Catalán R, Pujol N, Puig O, Guarch J, et al. 2010. Is memory impairment a rate limiter in cognitive behavioural therapy for chronic schizophrenia? Psychotherapy Psychosomatics 79(2): 129-130. https://doi. org $/ 10.1159 / 000276378$

73. Schoenbaum G, Roesch MR, Stalnaker TA, Takahashi YK. 2009. A new perspective on the role of the orbitofrontal cortex in adaptive behaviour. Nat Rev Neurosci 10(12): 885-892. https://doi.org/10.1038/ nrn2753

74. Sensky T, Turkington D, Kingdon D, Scott JL, Scott J, et al. 2000. A randomized controlled trial of cognitive-behavioral therapy for persistent symptoms in schizophrenia resistant to medication. Arch Gen Psychiatry 57(2): 165-172. https://doi.org/10.1001/archpsyc.57.2.165

75. Turkington D, Sensky T, Scott J, Barnes TR, Nur U, et al. 2008. A randomized controlled trial of cognitive-behavior therapy for persistent symptoms in schizophrenia: a five-year follow-up. Schizophr Res 98(13): 1-7. https://doi.org/10.1016/j.schres.2007.09.026

76. Green MJ, Phillips ML. 2004. Social threat perception and the evolution of paranoia. Neurosci Biobehav Rev 28(3): 333-342. https:// doi.org/10.1016/j.neubiorev.2004.03.006

77. Freeman D, Dunn G, Startup H, Pugh K, Cordwell J, et al. 2015. Effects of cognitive behaviour therapy for worry on persecutory delusions in patients with psychosis (WIT): a parallel, single-blind, randomised controlled trial with a mediation analysis. Lancet Psychiatry 2(4): 305313. https://doi.org/10.1016/S2215-0366(15)00039-5

78. Freeman D, Startup H, Dunn G, Černis E, Wingham G, et al. 2013. The interaction of affective with psychotic processes: a test of the effects of worrying on working memory, jumping to conclusions, and anomalies of experience in patients with persecutory delusions. J Psychiatry Res 47(12): 1837-1842. https://doi.org/10.1016/j.jpsychires.2013.06.016

79. Garety PA, Fowler DG, Freeman D, Bebbington P, Dunn G, et al. 2008. Cognitive--behavioural therapy and family intervention for relapse prevention and symptom reduction in psychosis: randomised controlled trial. Br J Psychiatry 192(6): 412-423. https://doi.org/10.1192/bjp. bp.107.043570

80. Peters E, Landau S, McCrone P, Cooke M, Fisher P, et al. 2010. A randomised controlled trial of cognitive behaviour therapy for psychosis in a routine clinical service. Acta Psychiat Scand 122(4): 302-318. https:// doi.org/10.1111/j.1600-0447.2010.01572.x

81. Wykes T, Brammer M, Mellers J, Bray P, Reeder C, et al. 2002. Effects on the brain of a psychological treatment: cognitive remediation therapy: functional magnetic resonance imaging in schizophrenia. $\mathrm{Br} \mathrm{J}$ Psychiatry 181: 144-152. https://doi.org/10.1192/bjp.181.2.144

82. Ramsay IS1, MacDonald AW. 2015. Brain correlates of cognitive remediation in schizophrenia: activation likelihood analysis shows preliminary evidence of neural target engagement. Schizophr Bull 41(6): 1276-1284. https://doi.org/10.1093/schbul/sbv025 